\title{
Morphological and Molecular Analysis of Fusarium lateritium, the Cause of Gray Necrosis of Hazelnut Fruit in Italy
}

\author{
S. Vitale, A. Santori, E. Wajnberg, P. Castagnone-Sereno, L. Luongo, and A. Belisario
}

First, second, fifth, and sixth authors: CRA-PAV Centro di Ricerca per la Patologia Vegetale, Via C. G. Bertero 22, 00156 Roma, Italy; and third and fourth authors: INRA UMR1301-UNSA-CNRS UMR6243, 400 Route des Chappes, BP 167, 06903 Sophia Antipolis Cedex, France.

Accepted for publication 14 January 2011.

\begin{abstract}
Vitale, S., Santori, A., Wajnberg, E., Castagnone-Sereno, P., Luongo, L., and Belisario, A. 2011. Morphological and molecular analysis of Fusarium lateritium, the cause of gray necrosis of hazelnut fruit in Italy. Phytopathology 101:679-686.

Fusarium lateritium is a globally distributed plant pathogen. It was recently reported as the causal agent of nut gray necrosis (NGN) on hazelnut. Isolate characterization within F. lateritium was undertaken to investigate how morphological and molecular diversity was associated with host and geographic origin. Morphological studies combined with inter-simple-sequence repeat (ISSR) analysis, and phylogenetic analyses using translation elongation factor $1 \alpha$ (TEF- $1 \alpha), \beta$-tubulin genes, and nuclear ribosomal DNA internal transcribed spacer (ITS) sequences were conducted to resolve relationships among $32 \mathrm{~F}$. lateritium isolates from NGN-affected hazelnut fruit, and 14 from other substrates or 8 from other

grayish-olive differing from the orange-yellow color of all other isolates from other hosts. Generally, isolates from NGN-affected fruit failed to produce sporodochia on carnation leaf agar. The influence of host and substrate on the genetic structure of $F$. lateritium was supported by ISSR and analyzed with principal coordinates analysis. A relationship between hazelnut and genetic variation was inferred. Phylogenetic analysis of ITS provided limited resolution while TEF- $1 \alpha$ and $\beta$-tubulin analyses allowed a clear separation between the European and non-European F. lateritium isolates retrieved from GenBank, regardless of host. Though morphological traits of $F$. lateritium isolates from hazelnut were generally uniform in defining a typical morphogroup, they were not yet phylogenetically defined. In contrast, the typology related to slimy deep orange cultures, due to spore mass, grouped clearly separated from the other $F$. lateritium isolates and revealed a congruence between morphology and phylogeny.
\end{abstract} hosts than hazelnut. Colonies of $F$. lateritium from hazelnut showed dark
Fusarium is a vast genus of $\approx 78$ species of ubiquitous fungi which includes plant pathogens, saprophytes, and endophytes. Fusarium lateritium Nees (Gibberella baccata (Wallr.) Sacc.) is the main species in the section Lateritium and has been reported on numerous hosts, mainly woody and fruit trees as well as shrubs and plants, where it causes wilt, tip or branch dieback, and cankers. There are $\approx 180$ host-pathogen combinations that include important fruit and woody species. $F$. lateritium has been the subject of numerous reports as a wound pathogen of tree species (17) and extensively investigated as the causal agent of chlorotic leaf distortion (CLD) on sweet potato (Ipomoea batatas) in the United States $(9,21)$.

In Italy, this pathogen has been reported as the agent of fruit rot on walnut (44) and olive (13) and, more recently, as the cause of twig cankers (5) and nut gray necrosis (NGN) $(4,37)$ of hazelnut (Corylus avellana). The disease caused on hazelnut fruit was named NGN because of the symptoms observed (4,36). Symptoms consist of a characteristic brown-grayish necrotic spot or patch on nuts and bracts, and sometimes on the petiole (4). Smallspored catenulate taxa related to Alternaria alternata were reported as agents of inner rot of hazelnut fruit contributing to the severity of NGN disease (6). Since its first occurrence in 2000, NGN has endangered the industry because of severe (up to 60\%) fruit drop. Damages have been relevant due to the importance of

Corresponding author: A. Belisario; E-mail address: alessandra.belisario@entecra.it

* The $\boldsymbol{e}$-Xtra logo stands for "electronic extra" and indicates that the online version contains one supplemental table.

doi:10.1094/PHYTO-04-10-0120

(C) 2011 The American Phytopathological Society nut production and trade for the economy of the country, because Italy is the second largest producer of hazelnut in the world after Turkey.

Results obtained with pathogenicity tests of $F$. lateritium reported in previous research $(7,36,37)$ supported the speculation that isolates of the pathogen obtained from hazelnut twig cankers and from $\mathrm{NGN}$-infected fruit might represent a homogeneous morphogroup within $F$. lateritium that was adapted to the host. This speculation was rooted in the observation that $F$. lateritium isolates obtained from hazelnut caused the typical NGN symptoms when inoculated on nuts coupled with an extremely abundant production of sporodochia on the colonized nuts. Conversely, $F$. lateritium isolates from other hosts were able to produce only a brown necrosis on the shell of $C$. avellana nuts with a few sporodochia, without penetrating inward (7). Traditionally, distinctive features of conidia and conidiation as well as morphology, growth rate, and color of colonies are informative for species identification within the genus Fusarium $(9,23,30)$. However, members of the genus Fusarium are commonly accepted to be difficult to identify at the species level if simply relying on morphological traits.

Molecular techniques have made a significant impact on fungal species identification as well as on phylogenetic and taxonomic studies, including the differentiation of intraspecific groupings $(24,31)$ or between very closely related species (19). These techniques include dominant and codominant highly variable molecular markers such as random amplified polymorphic DNA (RAPD), inter-simple-sequence repeats (ISSRs), and sequence data from a number of DNA regions. In addition, multiple gene genealogies have been used and sequence analyses of nuclear ribosomal DNA (nrDNA), $\beta$-tubulin ( $\beta$-tubulin), or translation 
elongation factor $1 \alpha$ (TEF-1 $\alpha$ ) have been broadly considered reliable in species or subspecies identification as well as in the vast Fusarium genus $(31,39)$. Hence, the molecular data, when combined with morphological and biological features, allow a more robust identification of unresolved taxa $(2,25,31)$.

Various studies refer to morphological and molecular characterizations of several Fusarium spp. but limited information is available on F. lateritium. This species has not been fully resolved and it is considered to be a species complex which might contain several taxa that need to be fully characterized (23). Previous characterizations based on RAPD and restriction fragment length polymorphism (RFLP) of intergenic spacer (IGS) and internal transcribed spacer (ITS) regions of nrDNA have revealed little genetic variation in isolates from sweet potato infected by CLD in comparison with isolates from other hosts (21). More recently, Geiser et al. (16) carried out a phylogenetic analysis within Fusarium section Lateritium on sequenced portions of $\beta$-tubulin and TEF- $1 \alpha$ genes to resolve $F$. xylarioides (teleomorph $G$. xylarioides), the causal agent of coffee wilt, from $F$. lateritium or F. stilboides. Similarly to F. avenaceum (27), F. lateritium can be considered to be a multiple phylogenetic species for its cosmopolitan nature as well as for its diverse host range.

Research on the characterization of isolates of $F$. lateritium from hazelnut was undertaken to investigate how morphological and molecular diversity were associated with host and geographic origin. More specifically, the objectives of this study were to (i) characterize isolates of $F$. lateritium from hazelnut for their morphological traits and to compare them with isolates form other plants; (ii) combine morphological and molecular data to generate a robust characterization of isolates associated with NGN or hazelnut twig canker; and (iii) determine the phylogenetic relationships among isolates of $F$. lateritium with respect to hazelnut versus other hosts, as well as geographic origin.

To accomplish these goals, differences between isolates of $F$. lateritium associated with NGN and those obtained from hazelnut other than fruit or other hosts were analyzed using phenotypic data (i.e., colony color, production of sporodochia on carnation leaf agar [CLA], host, and substrate) combined with molecularbased groupings of ISSR profiles. Phylogenetic analyses using three loci (ITS, $\beta$-tubulin, and TEF- $1 \alpha$ ) were performed. ISSRpolymerase chain reaction (PCR) profiles combined with the phenotypic features were investigated using principal coordinates analysis (PCoA).

The data provided with this study will be valuable to expand knowledge of the genetic variability among $F$. lateritium isolates and, ideally, will improve disease management practices by identifying sources of inoculum and isolate characteristics.

\section{MATERIALS AND METHODS}

Fungal isolates. In total, $54 \mathrm{~F}$. lateritium isolates were used for molecular studies; 51 of these isolates were also studied morphologically and by ISSR analysis. Sources of the isolates are listed in Table 1. Isolates of $F$. lateritium from hazelnut were recovered from twigs, pollen, symptomatic fruit, and bracts (affected by NGN) using standard phytopathological isolation techniques. Isolations were performed on potato dextrose agar (PDA) (Oxoid, Basingstoke, UK) and on the selective medium Nash-Snyder (NS) (28). To recover the fungus from pollen, mature catkins were kept $\approx 2$ days at $22 \pm 2{ }^{\circ} \mathrm{C}$ and sieved twice to obtain loose pollen grains. Subsequently, $1 \mathrm{~g}$ of pollen was suspended in $10 \mathrm{ml}$ of sterile distilled water (SDW) and stirred for $10 \mathrm{~min}$. Aliquots of $1 \mathrm{ml}$ of the suspension for each pollen sample were plated on each of five plates of NS medium. Following 7 to 14 days of incubation of plates at 20 to $22^{\circ} \mathrm{C}$ in darkness, putative $F$. lateritium colonies were transferred onto PDA. Isolates from hosts other than hazelnut or provided from scientific institutions were firstly subcultured on PDA. The isolate ISPaVe 2007 = PD90/286, identified as F. lateritium by H. Nirenberg (supplied by Mr. Johan Meffert, Plantenziektenkundige Dienst, Geertjesveg, Wageningen, The Netherlands) was used as reference isolate. Microscopic characterization for species identification was carried out on both PDA and on CLA (15) following Booth (8), Nelson et al. (30), and Leslie and Summerell (23). All of the isolates used in this study were preserved on slant carrot agar tubes and on filter paper.

Morphological characterization. Macroscopic and microscopic characteristics were examined for $51 \mathrm{~F}$. lateritium cultured single-spore isolates or from single hyphal tips (39). All isolates were subcultured on PDA and grown at $22^{\circ} \mathrm{C}$ in the dark for 10 days. Then, a 5-mm-diameter plug from the colony margin was placed in the center of a $90-\mathrm{mm}$ petri dish containing PDA and incubated for 20 days under the conditions described above, after which morphological and colony characteristics were recorded. Three replicates for each isolate were used and the experiment was repeated twice. Pigmentation assessment was based on Kelly and Judd color tables (22). Color was scored as 1 for dark grayish-olive and 2 for orange-yellow colony appearance. The production of sporodochia on CLA was induced on subcultures incubated at $22^{\circ} \mathrm{C}$ under near-UV (nUV) light and checked within 10 days of incubation (39). The length and width of 50 macroconidia for each sporulating isolate on CLA and the number of septa were measured. Samples were mounted in lactic acid.

DNA extraction. To investigate the molecular characteristics of $F$. lateritium isolates, the mycelium of 20-day-old cultures grown on PDA was scraped directly from agar plates and ground to a fine powder under liquid nitrogen using a sterile mortar and pestle. Total DNA was extracted following the protocol of the Wizard genomic DNA purification kit (Promega Corp., Madison, WI).

ISSR amplification. The $51 \mathrm{~F}$. lateritium isolates subjected to phenotypic characterization were submitted to ISSR analysis. Isolates ISPaVe1972, 2009, and 2010 were not included in either the phenotypic characterizations or the ISSR analysis because they were collected later. Among a total of 26 ISSR primers tested, 18 primers- $(\mathrm{AAG})_{6},(\mathrm{AC})_{8} \mathrm{~T},(\mathrm{ACA})_{5},(\mathrm{AG})_{8} \mathrm{TA},(\mathrm{AG})_{8} \mathrm{TC}$, $(\mathrm{CAA})_{5},(\mathrm{CCA})_{5},(\mathrm{CTC})_{4},(\mathrm{GA})_{6} \mathrm{GG},(\mathrm{GA})_{8} \mathrm{C},(\mathrm{GA})_{8} \mathrm{~T},(\mathrm{GACA})_{4}$, $(\mathrm{GAG})_{4} \mathrm{GC},(\mathrm{GT})_{6} \mathrm{CC},(\mathrm{GTC})_{6},(\mathrm{GTG})_{5}, \mathrm{M} 13$, and $\mathrm{T} 3 \mathrm{~B}$-were selected based upon the production of distinct and reproducible polymorphic banding patterns. Primers were synthesized by MWG Eurofins (Germany). PCR reactions for all primer sets were performed using a thermocycler Gene Amp System 9700 (Applied Biosystems, Foster City, CA). For each primer-isolate combination, amplifications were repeated at least three times in order to assure consistency. Negative controls, using sterile double-distilled $\mathrm{H}_{2} \mathrm{O}$ instead of DNA, were included in each experiment. A standard PCR reaction was carried out with 40 cycles of $94^{\circ} \mathrm{C}$ for $1 \mathrm{~min}, 50^{\circ} \mathrm{C}$ for $1.5 \mathrm{~min}$, and $72^{\circ} \mathrm{C}$ for $2 \mathrm{~min}$. Amplification products were electrophoresed on a $1.5 \%$ agarose gel in $0.5 \times$ Tris-borate EDTA buffer, stained with ethidium bromide, and visualized under UV light, and images were acquired by Gel Doc 2000 System (Bio-Rad, Hercules, CA). A commercial gel documentation system (Quantity One 4.2.2; Bio-Rad) was used as support for the scoring of band as presence $(=1)$ or absence (=0).

Amplification of ITS, TEF-1 $\alpha$, and $\beta$-tubulin gene regions. The nuclear ribosomal ITS region was amplified with the ITS5 and ITS4 primer pair (43) using as cycling parameters $95^{\circ} \mathrm{C}$ for $3 \mathrm{~min}$; followed by 35 cycles of $30 \mathrm{~s}$ at $94^{\circ} \mathrm{C}, 30 \mathrm{~s}$ at $55^{\circ} \mathrm{C}$, and $1 \mathrm{~min}$ at $72^{\circ} \mathrm{C}$; and a final extension for $5 \mathrm{~min}$ at $72^{\circ} \mathrm{C}$. The amplification of the TEF- $1 \alpha$ region was performed with EF1 and $\mathrm{EF} 2$ primer pair (34) starting with $8 \mathrm{~min}$ of denaturation at $95^{\circ} \mathrm{C}$; followed by 35 cycles of $15 \mathrm{~s}$ at $95^{\circ} \mathrm{C}, 20 \mathrm{~s}$ at $53^{\circ} \mathrm{C}$, and $1 \mathrm{~min}$ at $72^{\circ} \mathrm{C}$; and a final extension for $5 \mathrm{~min}$ at $72^{\circ} \mathrm{C}$. For amplification of the $\beta$-tubulin gene region, the primer pair benA-T1 forward 
and benA-T2 reverse was used (33) and amplification started at $94^{\circ} \mathrm{C}$ for $5 \mathrm{~min}$; then, 40 cycles of $94^{\circ} \mathrm{C}$ for $35 \mathrm{~s}, 53^{\circ} \mathrm{C}$ for $55 \mathrm{~s}$, and $72^{\circ} \mathrm{C}$ for $2 \mathrm{~min}$; and a final cycle of $7 \mathrm{~min}$ at $72^{\circ} \mathrm{C}$. Amplification products were stained and visualized as described above.

DNA sequencing. Templates were sequenced in both directions with primers used in amplification. Prior to sequencing, PCR products were purified using NucleoSpin Extract II (MachereyNagel, Germany) according to the manufacturer's instructions. Cycle-sequencing reactions were performed at Bio-Fab Research s.r.l. (Rome) using the BigDye system (version 3.1 dye terminator; Applied Biosystems). The consensus sequences were aligned with additional ITS, TEF- $1 \alpha$, or $\beta$-tubulin accessions obtained from GenBank. Alignments were visually inspected and edited manually for small (single-nucleotide) indels. ClustalW (41) was used to generate consensus sequences (based on $5^{\prime}$ and $3^{\prime}$ sequence data) and to align the consensus sequence to each other and to the sequences in GenBank. BLAST (1) was used to perform similarity searches comparing the $F$. lateritium sequences generated in this work with those in GenBank. Sequences of $F$. lateritium or belonging to Fusarium spp. found in section Lateritium were used for comparison.

Nucleotide sequence accession numbers. All DNA sequence data of the $54 \mathrm{~F}$. lateritium isolates regarding the three nuclear loci generated for this study have been deposited in GenBank under accession nos. FN547420 to FN547473 for the ITS region and FN550947 to FN551000 and FN554618 to FN554671 for TEF- $1 \alpha$ and $\beta$-tubulin genes, respectively.
Phylogenetic analyses. The $\beta$-tubulin and TEF- $1 \alpha$ gene region sequences generated in this study were analyzed together with the TEF- $1 \alpha$ and $\beta$-tubulin sequences produced by Geiser et al. (16) and retrieved from GenBank. Homologous sequences from $F$. xylarioides were used as an outgroup (16). The ITS sequences generated in this study were analyzed using one corresponding sequence available in databanks for comparison. Sequences generated in this study for the isolate ISPaVe2007 (= PD90/286) were designated as reference sequences.

The ITS, $\beta$-tubulin, and TEF- $1 \alpha$ sequence data sets were each aligned using the MUSCLE program (11) available online (www.ebi.ac.uk/muscle/) using the default parameters that have been designed to give the best average benchmark accuracy, as detailed in the original description of the algorithm (12). Alignments were visually inspected and manual adjustments made where necessary. Preliminary phylogenetic trees were reconstructed for each data set separately using two methods of reconstruction based on very different algorithms (i.e., neighbor-joining $[\mathrm{NJ}]$ and maximum parsimony $[\mathrm{MP}]$ ) as implemented in PAUP* version $4.0 \mathrm{~b} 10$ (40). The Kimura-two-parameter model was used to generate the NJ trees. For MP analyses, the heuristic search option was used, with stepwise additional and tree bisection-reconnection branch-swapping algorithm. All characters were run unordered and of equal weight and gaps were treated as missing data. Branches of zero length were collapsed and all multiple, equally parsimonious trees were saved. For all analyses, 1,000 bootstrap replicates (14) were performed to evaluate the node

TABLE 1. Origin and characteristics of Fusarium isolates used in this study

\begin{tabular}{|c|c|c|c|c|c|c|c|}
\hline \multirow[b]{2}{*}{ Species } & \multirow[b]{2}{*}{ Strain } & \multirow[b]{2}{*}{ Host } & \multirow[b]{2}{*}{ Origin } & \multicolumn{2}{|c|}{ Substrate } & \multirow[b]{2}{*}{ Color $^{\mathrm{c}}$} & \multirow[b]{2}{*}{$\mathrm{CLA}^{\mathrm{d}}$} \\
\hline & & & & Type & Code $^{b}$ & & \\
\hline Fusarium lateritium & ISPaVe1874, 1877, 1882, 1976 & Corylus avellana & Italy (Latium) & NGN & 1 & 1 & 1 \\
\hline F. lateritium & $\begin{array}{l}\text { ISPaVe1875, 1876, 1883, 1886, 1888, 1894, } \\
\text { 1941, 1969, 1970, 1971, 1973, 1975, 1977, } \\
\text { 1978, 1979, 1980, 1981, 1982, 1983, 1985, } \\
\text { 1986, 1987, 1988, 1989, 1990 }\end{array}$ & C. avellana & Italy (Latium) & NGN & 1 & 1 & 2 \\
\hline F. lateritium & ISPaVe2035 & C. avellana & Italy (Campania) & NGN & 1 & 1 & 2 \\
\hline F. lateritium & ISPaVe1936, 1937, 1938, 1939, 1940, 1942 & C. avellana & Italy (Latium) & Twig & 2 & 1 & 1 \\
\hline F. lateritium & ISPaVe1972 & C. avellana & Italy (Latium) & NGN & 1 & ND & ND \\
\hline$F$. lateritium & ISPaVe1966 & C. avellana & Italy (Piedmont) & Twig & 2 & 1 & 1 \\
\hline F. lateritium & ISPaVe2002, 2003, 2004, 2008, 2011 & C. avellana & Italy (Latium) & Pollen & 3 & 1 & 1 \\
\hline$F$. lateritium & ISPaVe2009, 2010 & C. avellana & Italy (Latium) & Pollen & 3 & ND & ND \\
\hline$F$. lateritium & ISPaVe1960 & Juglans regia & Italy (Campania) & Bark & 2 & 1 & 1 \\
\hline F. lateritium & ISPaVe2019 & J. regia & Italy (Latium) & Pollen & 3 & 2 & 1 \\
\hline$F$. lateritium & ISPaVe1974, 1984 & Actinidia deliciosa & Italy (Latium) & Twig & 2 & 2 & 1 \\
\hline$F$. lateritium & ISPaVe1995 & Populus sp. & France & Twig & 2 & 2 & 1 \\
\hline$F$. lateritium & ISPaVe1996 f & Olea europea & Italy (Calabria) & Twig & 2 & 2 & 1 \\
\hline$F$. lateritium & ISPaVe2005 & Triticum durum & Italy (Apulia) & Caryopsis & 3 & 2 & 1 \\
\hline F. lateritium & ISPaVe2007= PD90/286 & Malus sp. & The Netherlands & Twig & 2 & 2 & 1 \\
\hline$F$. lateritium & BBA65248 & N/A & N/A & N/A & N/A & N/A & N/A \\
\hline F. lateritium/stilboides & $\mathrm{L}-81^{\mathrm{h}}, \mathrm{L}-82$ & Orange tree & New Caledonia & Twig & N/A & N/A & N/A \\
\hline$F$. lateritium/stilboides & L-83, L-84, L-86 & Coffee & New Guinea & Berry & N/A & N/A & N/A \\
\hline$F$. lateritium/stilboides & L-87 & Coffee & New Caledonia & Berry & N/A & N/A & N/A \\
\hline$F$. lateritium/stilboides & L-107 & Coffee & Zimbabwe & N/A & N/A & N/A & N/A \\
\hline$F$. lateritium/stilboides & L-110, L-112 & Coffee & New Guinea & Twig & N/A & N/A & N/A \\
\hline$F$. lateritium & L-120 & Coffee & N/A & N/A & N/A & N/A & N/A \\
\hline$F$. lateritium/stilboides & L-200 & Soil & Philippines & N/A & N/A & N/A & N/A \\
\hline$F$. lateritium & L-375 & Coffee & Brazil & Dry berry & N/A & N/A & N/A \\
\hline$F$. lateritium & L-376 & Coffee & Brazil & Seed & N/A & N/A & N/A \\
\hline F. stilboides & L-402 & Coffee & Malawi & Bark & N/A & N/A & N/A \\
\hline F. stilboides var. stilboides & L-405 & Citrus & New Zealand & N/A & N/A & N/A & N/A \\
\hline F. xylarioides & L-128 & Coffee & Ethiopia & N/A & N/A & N/A & N/A \\
\hline F. xylarioides & L-399 & Coffee & Uganda & N/A & N/A & N/A & N/A \\
\hline
\end{tabular}

${ }^{\text {a }} \mathrm{NGN}=$ fruit affected by nut gray necrosis; $\mathrm{ND}=$ not determined, these isolates were used for sequence analysis only; $\mathrm{N} / \mathrm{A}=$ information not available.

${ }^{\mathrm{b}}$ Codes stay: 1 = from hazelnut fruit, 2 = from canker, $3=$ from pollen.

c Colony color: $1=$ dark grayish olive and $2=$ orange yellow.

d Sporulation on carnation leaf agar (CLA): $1=$ present and $2=$ absent.

e Strain supplied by Dr. Philippe Loevenbruck, Direction Régionale de l'Agriculture et de la Forêt, Ministère de l'Agriculture et de la Pêche, Nancy, France.

${ }^{f}$ Strain supplied by Prof. Gaetano Magnano di San Lio, Università degli Studi Mediterranea di Reggio Calabria, Italy.

g Strain supplied by Mr. Johan Meffert, Plantenziektenkundige Dienst, Geertjesveg, Wageningen, The Netherlands.

${ }^{\mathrm{h}}$ Strain information derived from Geiser et al. (16). 
support of the generated trees. Subsequently, considering sequence data from the individual genes as independent characters, topological similarity between individual MP and NJ trees was determined using a pairwise tree-comparison algorithm (32) available online (www.mas.ncl.ac.uk/ ntmwn/phylo_comparison/ pairwise.html), and a combined analysis was performed according to the total evidence approach (20). Because the ITS data set contained just one single sequence available in GenBank such as BBA65248, only the $\beta$-tubulin and TEF- $1 \alpha$ data were included in this combined analysis, and phylogenetic information was inferred in the same way as described above. Topological similarity between the MP and NJ trees resulting from the combined analysis was also determined as described above.

Fingerprint analysis and combination with descriptive parameters. For ISSR-primed PCR, bands were scored and a binary data matrix generated. From this matrix, pairwise similarity among isolates was determined according to $\mathrm{Nei}$ and $\mathrm{Li}$ (29), using PAUP* version $4.0 \mathrm{~b} 10$ (40). These pairwise similarities were use to perform a PCoA using the PROC MDS and
PRINCOMP procedures in the SAS/STAT package (38). The analysis produced the coordinates of the 51 isolates onto a twodimensional plan that was then used to represent the association between phenotypic characters of $F$. lateritium isolates and ISSR profile data in a Euclidian space. In order to increase the legibility of factorial plan, ellipses representing 5\% confidence intervals of average locations were computed and drawn to describe the relationships between isolates on the basis of their ISSR profile combined with each phenotypic feature considered; namely, color of the colony, host, substrate, and production of sporodochia on CLA.

\section{RESULTS}

Morphological features. Based on general colony morphology, the $51 \mathrm{~F}$. lateritium isolates could be placed in two main groups: dark grayish-olive and orange-yellow (scored as 1 and 2, respectively) (Table 1; Fig. 1). The dark grayish-olive group (group 1) contained 43 isolates from hazelnut plus ISPaVe1960
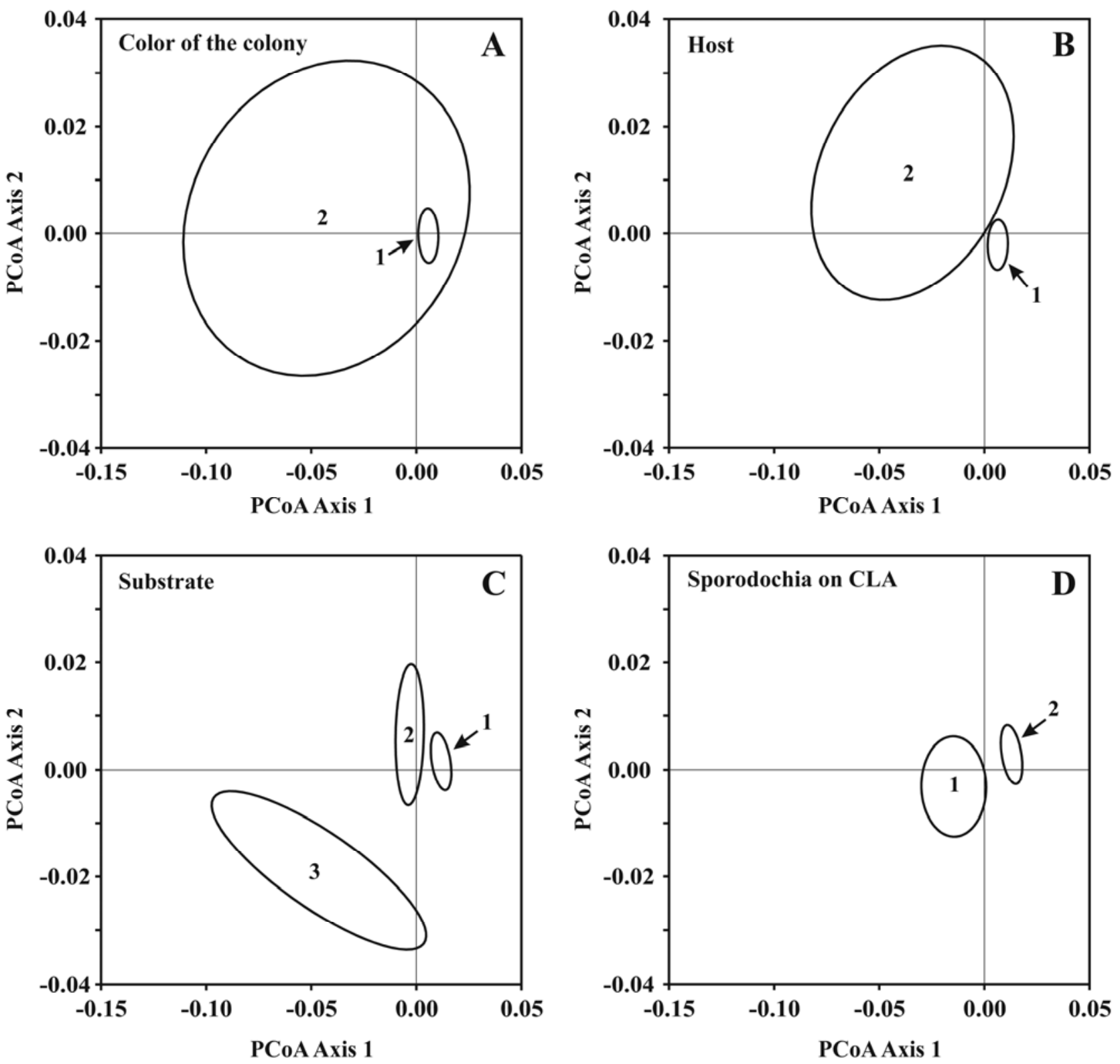

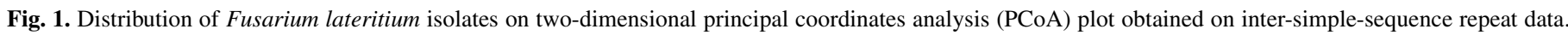

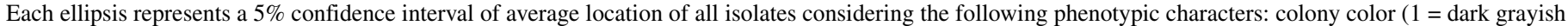

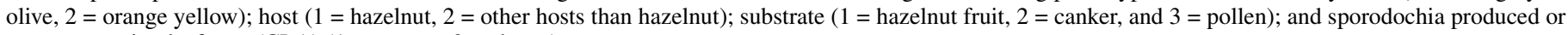
not on carnation leaf agar (CLA) $(1=$ present, $2=$ absent $)$. 
from walnut bark canker. In turn, the orange-yellow group (group 2 ), which showed the typical color reported for $F$. lateritium $(8,23,30)$, comprised seven isolates from hosts other than hazelnut. Amidst those isolates with orange-yellow color, ISPaVe2005 (from durum wheat caryopsis) and ISPaVe2019 (from walnut pollen) showed an extremely abundant sporulation on PDA and could be ascribed to the typology related to slimy, deep-orange cultures due to spore mass described by Booth (8). Isolates of $F$. lateritium from $\mathrm{NGN}$-affected fruit produced rare embedded sporodochia on PDA as well as macroconidia on loose, slender conidiophores. Generally, the NGN F. lateritium isolates failed to produce sporodochia on CLA within 10 days of incubation under nUV (scored as 2) (Table 1; Fig. 1), with the exception of four isolates (ISPaVe1874, 1877, 1882, and 1976). Conversely, all the other isolates, including those obtained from hazelnut twig cankers, produced sporodochia on CLA (scored as 1) (Table 1; Fig. 1). No microconidia were observed. Substrates from which isolates were recovered were scored as $1=$ hazelnut fruit, $2=$ canker, and 3 = pollen (Table1; Fig. 1).

Overall, there were not obvious differences between dark grayish-olive and orange-yellow groups with respect to conidial morphology. Macroconidia ( 26 to 50 by 3 to $4 \mu \mathrm{m}$ ) obtained from sporodochia on CLA were thin, falcate to almost straight, with parallel walls and apical cell with a distinct beak, and three to five septate.

ISSR-PCR analysis. In total, 249 clear and reproducible polymorphic bands of 300 to 2,000 bp were identified following PCR with the 18 selected ISSR primers. No differences were observed between repeated experiments. The presence or absence of these bands was used to analyze proximities between patterns of isolates by means of PCoA on pairwise similarities. To assess the relatedness between the isolates, pairwise similarities were calculated using Nei and Li's distances (29) based on ISSR fingerprints. Similarities ranged from a maximum of 1.000 to a minimum of 0.803 or 0.930 when the two isolates ISPaVe2005 and ISPaVe2019, which had the slimy deep orange appearance, were included or excluded, respectively.

The comparative analysis of the polymorphic profiles in combination with the phenotypic parameters was considered, and the coordinates of the 51 isolates of $F$. lateritium produced by a PCoA based on ISSR profiles were grouped according to their different phenotypic features (Fig. 1). Considering the color of the colony (Fig. 1A), no distinct groups were obtained and the dark grayish-olive colonies (scored as 1) were included in the wider group of isolates with orange-yellow appearance. In turn, the PCoA scatter plot led us to distinguish between isolates of $F$. lateritium from hazelnut (scored as 1) and those from other hosts (scored as 2) (Fig. 1B). Moreover, isolates from hazelnut fruit (scored as 1) were highly differentiated from those from pollen (scored as 3) and closer to those from cankers (scored as 2), though clearly separated (Fig. 1C). Considering the factor "substrate," the analysis provided evidence that isolates having the same host but different origin clustered in separate groups, supporting the specificity of $F$. lateritium NGN isolates. As expected, two distinct groups were plotted based on sporodochia formation on CLA, and the group of isolates unable to produce sporodochia (scored as 2) included only the $F$. lateritium NGN isolates (Fig. 1D). In all representations and for each character considered, $F$. lateritium NGN isolates clustered as a very low variable group. The group of isolates from hazelnut in general, and from NGN-affected fruit in particular, tended to be concentrated around the origin of the axes (Fig. 1).

Phylogenetic analyses. The lengths of the sequence alignments, including gaps, were 530, 717, and 731 sites for the ITS, $\beta$-tubulin, and TEF- $1 \alpha$ data sets, respectively. Comparison of the outcome of the separate analyses of the three data sets showed, in each case, an extreme congruence between the topologies of the resulting trees generated by either the NJ or MP approach. In particular, overall topological similarities for the $\beta$-tubulin and TEF- $1 \alpha$ individual MP and NJ topologies were 47.9 and $78.3 \%$, respectively. In addition, for each of these two methods, the ITS, $\beta$-tubulin, and TEF- $1 \alpha$ analyses yielded phylogenetic inferences that were not in significant conflict as assessed by bootstrap support. Consequently, we built a matrix of the two larger data sets (i.e., $\beta$-tubulin and TEF- $1 \alpha$ ) and performed global analyses. The congruence between the resulting MP and NJ tree topologies was high (overall topological score of $80.7 \%$ ), and the nodes defining the main clades of the trees were conserved (topological scores of $100 \%$ ) (Fig. 2). Therefore, in order to provide a readerfriendly view of the results, only the NJ analysis of the $\beta$-tubulin and TEF- $1 \alpha$ combined data set was described in detail (Fig. 2).

Overall, the combined phylogenetic analysis was conducted on sequences from 71 isolates, including the 54 European isolates characterized in this study and 15 isolates from the Southern hemisphere, corresponding to $F$. lateritium and $F$. lateritium/ stilboides, and 2 isolates of $F$. xylarioides, for which the homologous sequences were retrieved from GenBank. For the European isolates, partial sequences of $548 \mathrm{bp}$ for the $\beta$-tubulin and 644 to $647 \mathrm{bp}$ for TEF- $1 \alpha$ genes were generated. The global alignment resulting from the combination of the $\beta$-tubulin and TEF- $1 \alpha$ sequences, including gaps, comprised 1,448 characters. Basically, two major clades could be identified in the resulting NJ tree (Fig. 2). Clade 1 (100\% bootstrap support) included the 54 European isolates while clade 2 included the 15 isolates from the Southern hemisphere. In clade 1, 52 of the 54 isolates were distributed into two main subclades (a and b, with 51 and $82 \%$ bootstrap support, respectively). The sequences from the two remaining European isolates (ISPaVe2005 and ISPaVe2019, from durum wheat caryopsis and walnut pollen, respectively) formed an independent cluster (70\% bootstrap support) with a basal position in clade 1 . Within each subgroup, very little genetic differentiation of the isolates was resolved. The isolate ISPaVe2007, originally sampled from Malus spp., held a distinct, basal position in subgroup a. However, the European F. lateritium NGN isolates did not form a monophyletic cluster, and were generally scattered within isolates from substrate other than NGN-infected fruit or from hosts other than hazelnut, despite their peculiar phenotypic characters. The 15 combined sequences retrieved from GenBank, corresponding to isolates from the Southern hemisphere, were well separated from the European isolates, and fell into clade 2 with $100 \%$ bootstrap support. They exhibited a higher level of genetic diversity and could unambiguously be distributed into three highly supported subclades (a, b, and c), which reproduced a grouping similar to that reported in the original work of Geiser et al. (16). Both clades 1 and 2 were clearly distinct from the $F$. xylarioides ( $G$. xylarioides) outgroup.

\section{DISCUSSION}

This work revealed the morphological, molecular, and phylogenetic relationships among $F$. lateritium isolates obtained from hazelnut fruit affected by NGN with those obtained from hazelnut twig cankers and from other substrates and hosts. The study showed that the NGN Fusarium isolates analyzed belong to the $F$. lateritium species based on both the conidial morphology and size $(8,23,30)$ and their genetic similarity to the reference isolate ISPaVe2007. Data indicate that $F$. lateritium isolates from NGNaffected fruit are not phylogenetically distinct from $F$. lateritium isolates from diverse substrates and hosts. In turn, the genetic variation observed among these isolates is related to their geographical origin. For instance, the European $F$. lateritium isolates were phylogenetically distinct from the non-European $F$. lateritium and $F$. lateritium/stilboides retrieved from GenBank. Both European and non-European $F$. lateritium and $F$. lateritium/stilboides were clearly distinct from the $F$. xylarioides outgroup. 
Although there was morphological variation among European F. lateritium isolates, they fit within the range of descriptions used for $F$. lateritium and, in particular, there was a full correspondence with the pigmentation and mycelial characteristics reported by
Booth (8). Based on colony color, two main subgroups were evident (Table 1): the dark grayish-olive group of $F$. lateritium isolates from hazelnut (NGN-affected fruit, twig canker, and pollen) and the orange-yellow group of all the other F. lateritium

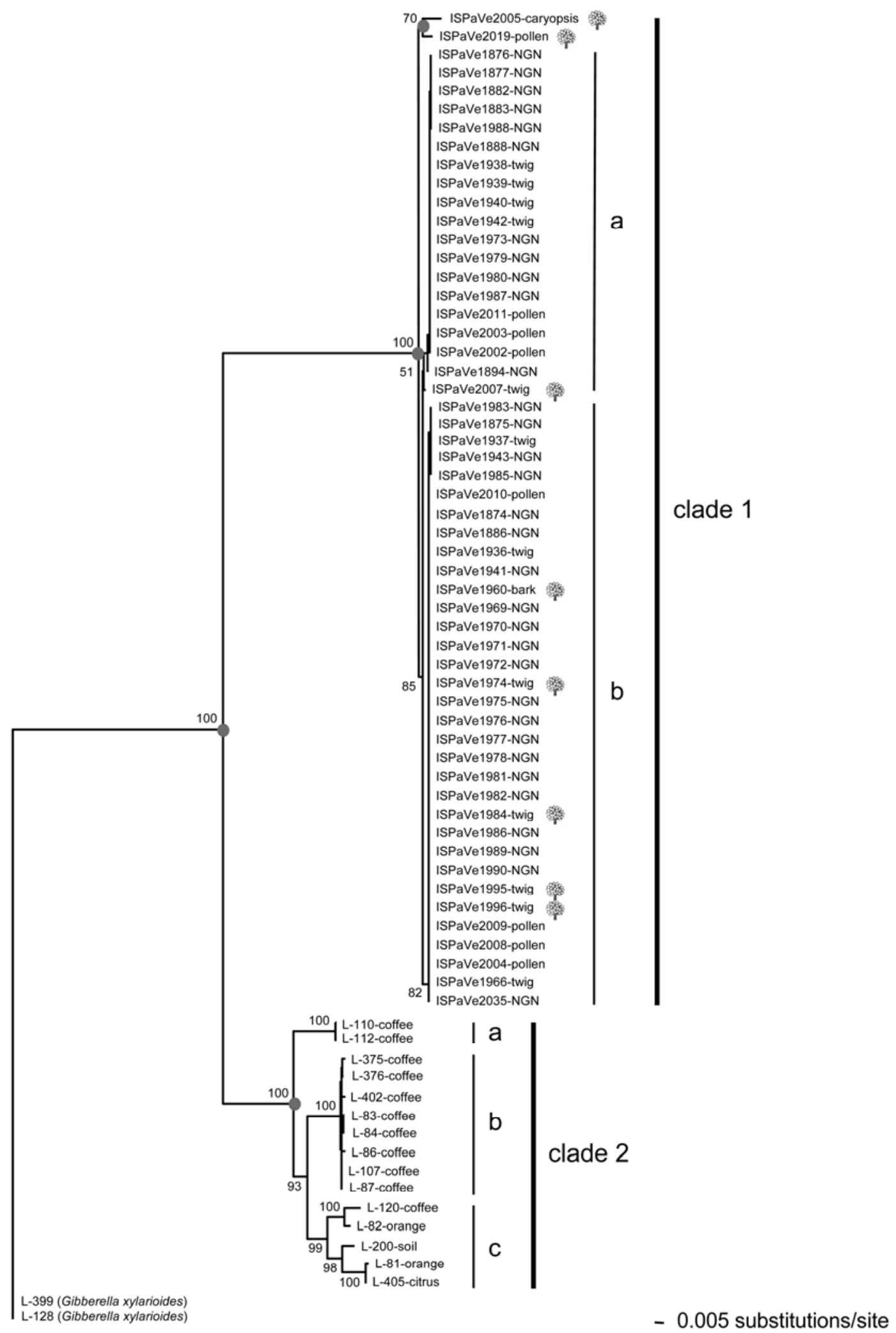

Fig. 2. Tree phylogram from neighbor-joining (NJ) inference analysis of combined data from $\beta$-tubulin and translation elongation factor-1 $\alpha$ (TEF-1 $\alpha$ ) sequences of Fusarium lateritium isolates. The tree was generated using the Kimura-two-parameter model as implemented in PAUP* version 4.0b10. Bootstrap support was calculated from 1,000 replicates and values $>50 \%$ are indicated at the corresponding nodes. Isolate codes are as in Table 1. Sequences L399 and L128 from $G$. xylarioides were considered to be outgroup in this analysis. In clade 1, symbols to the right indicate isolates from other hosts than hazelnut. Nodes that were conserved between the $\mathrm{NJ}$ and the maximum-parsimony analysis of the data (topological score of 100\%) are shown with gray dots. 
isolates. Color remained stable even after subculturing. The dark grayish-olive pigmentation is a peculiar feature of the $F$. lateritium isolates from hazelnut, which is the origin of the typical gray spot or patch in the case of infection of nuts and bracts, and from which the name of NGN disease is derived. In this respect, we answered the first question of whether the host does influence the morphological characteristics, giving rise to a typical morphogroup within the broader $F$. lateritium complex, for which different pigmentations have been reported (8), though it was not supported by ISSR profile clustering and by PCoA plotting (Fig. 1A). In turn, isolates from hazelnut formed a homogeneous group located just at the border of the highly variable group of $F$. lateritium isolates obtained from other hosts (Fig. 1B). The field observations of a frequent association between the presence of cankers on hazelnut twigs and the occurrence of NGN disease $(5,36)$ is well represented in Figure $1 \mathrm{C}$, where F. lateritium NGN isolates grouped fairly close to isolates from cankers. Cankers may represent a source of inoculum to NGN for the abundant production of sporodochia in correspondence to lesions $(5,7)$. Nevertheless, $F$. lateritium NGN isolates tend to differ from those obtained from twigs, losing the capacity of producing sporodochia on CLA. This characteristic allowed the differentiation of the $F$. lateritium isolates into two main subgroups: no production of sporodochia, typical of most of the NGN isolate set, and the sporulation on CLA displayed by all the other $F$. lateritium isolates. This characteristic enhanced the separation between NGN and non-NGN $F$. lateritium isolates displayed in Figure 1D. It could be inferred that the passage from the colonization of twigs to nuts generates a sort of specialization to the host, and isolates obtained from NGN-affected nuts tend to sporulate on hazelnut only.

PCoA proved to be a powerful method for analyzing and displaying ISSR-PCR data, confirming its sensitivity in representing the variability obtained from molecular and phenotypic data. Moreover, the ISSR-PCR-based technique provided stable and reproducible results. ISSR markers have been successfully used in gene tagging (35) to determine population structure and genetic variability within various fungal species. Furthermore, these markers have been used to discriminate among individual fungal isolates (10,25), including several Fusarium spp. or formae speciales; namely, F. culmorum (18), F. solani (45), F. oxysporum f. sp. ciceris (3), and F. solani f. sp. phaseoli (26).

In contrast to differences that emerged in the phenotypic characterization, the molecular markers employed (ITS, TEF-1 $\alpha$, and $\beta$-tubulin) failed to resolve a phylogenetic structure in the $F$. lateritium clades with regard to the NGN isolates. This lack could derive from an inadequate resolution of the markers in relation to the characters examined as reported for lisianthus isolates within $F$. avenaceum (27). The ITS region was insufficient for the resolution of subspecific groups because it was also reported for closely related species within the Fusarium genus (42). Though the TEF- $1 \alpha$ gene has been used in most studies for phylogenetic resolution within and between intraspecific groups, it did not contain enough variation to separate $F$. lateritium NGN or hazelnut isolates from the others. However, these same loci showed moderate to high levels of phylogenetic structure in other morphologically defined species of Fusarium, including the F. lateritium species complex, with regard to $F$. xylarioides (16). Similarly to $F$. avenaceum from lisianthus, the $F$. lateritium isolates analyzed in this study were first identified morphologically. However, the correlation between morphological and phylogenetic species concepts may differ from some Fusarium morphospecies that have broad host ranges, where a morphospecies corresponds to multiple phylogenetic species (27).

The two isolates ISPaVe2005 and ISPaVe2019, from wheat caryopsis and walnut pollen, respectively, held a basal position in the clade of the European $F$. lateritium isolates, and were clearly separated from either subclade a or b. Although these isolates were unambiguously identified as $F$. lateritium based on phenotypic features, their unique features of an extremely abundant sporulation on PDA coupled with a peculiar colony morphology (data not shown) indicate a phylogenetic uniqueness that deserves further studies. This suggests that the inclusion of additional and more diverse isolates should provide a phylogenetic resolution to subspecific morphogrouping.

This study further demonstrates the complexity of $F$. lateritium species, and the phylogenetic analysis of the two loci TEF- $1 \alpha$ and $\beta$-tubulin, analyzed separately or combined, revealed a clear separation between the European and non-European $F$. lateritium isolates regardless of the host. Consequently, the geographical area of origin might have an impact on the genomic differentiation within $F$. lateritium complex rather than the host. The phylogenetic analysis performed on a number of $F$. lateritium isolates from different geographic areas and from several hosts or substrates will benefit future research that might lead to the resolution of new taxa within the $F$. lateritium complex.

In conclusion, geographic origin had an impact on phylogeny in $F$. lateritium. In turn, morphological traits of $F$. lateritium isolates from hazelnut, though they were generally uniform in defining a typical morphogroup, were not yet phylogenetically defined. Nevertheless, the typology related to slimy deep orange cultures, due to spore mass, grouped clearly separated from the other $F$. lateritium isolates and revealed a congruence between morphology and phylogeny.

Additional investigations of isolates from a larger host range and different geographic areas based on several informative genetic loci should provide a clearer picture of the phylogeny of the F. lateritium species complex.

\section{ACKNOWLEDGMENTS}

This research was granted by the project FRUMED, "Ricerche per il miglioramento della frutticoltura meridionale", and by the project COLMIA, "Collezione di microrganismi di interesse agrario, industriale ed ambientale", financed by the Italian Ministry of Agricultural Alimentary and Forest Politics. We thank M. Casella, who drew our attention to the occurrence of an unusual symptomatology that was subsequently named nut gray necrosis of hazelnut; and J. Meffert for having supplied the F. lateritium isolate ISPaVe2007 = PD90/286.

\section{LITERATURE CITED}

1. Altschul, S. F., Madden, T. L., Schäffer, A. A., Zhang, J., Zhang, Z., Miller, W., and Lipman, D. J. 1997. Gapped BLAST and PSI-BLAST: A new generation of protein database search programs. Nucleic Acids Res. 25:3389-3402.

2. Alves, A., Crous, P. W., Correia, A., and Phillips, A. J. L. 2008. Morphological and molecular data reveal cryptic speciation in Lasiodiplodia theobromae. Fungal Divers. 28:1-13.

3. Barve, M. P., Haware, M. P., Sainani, M. N., Ranjekar, P. K., and Gupta, V. S. 2001. Potential of microsatellites to distinguish four races of Fusarium oxysporum f. sp. ciceris prevalent in India. Theor. Appl. Genet. 102:138-147.

4. Belisario, A., Coramusi, A., Civenzini, A., and Maccaroni, M. 2003. La necrosi grigia della nocciola. Inf. Agrar. 6:71-72.

5. Belisario, A., Maccaroni, M., and Coramusi, A. 2005. First report of twig canker of hazelnut caused by Fusarium lateritium in Italy. Plant Dis. 89:106.

6. Belisario, A., Maccaroni, M., Coramusi, A., Corazza, L., Figuli, P., and Pryor, B. M. 2004. First report of Alternaria species groups involved in disease complexes of hazelnut and walnut fruit. Plant Dis. 88:404.

7. Belisario, A., and Santori, A. 2009. Gray necrosis of hazelnut fruit: a fungal disease causing fruit drop. Acta Hortic. 845:501-505.

8. Booth C. 1971. The Genus Fusarium. Commonwealth Mycological Institute, Kew, UK.

9. Clark, C. A., Valverde, R. A., Wilder-Ayers, J. A., and Nelson, P. E. 1990. Fusarium lateritium, causal agent of sweet potato chlorotic leaf distortion. Phytopathology 80:741-744.

10. Cook, B. M., Gareth, J. D., and Kaye, B. 2006. The Epidemiology of Plant Diseases. Springer, Dordrecht, The Netherlands.

11. Edgar, R. C. 2004. MUSCLE: multiple sequence alignment with high 
accuracy and high throughput. Nucleic Acids Res. 32:1792-1797.

12. Edgar, R. C. 2004. MUSCLE: a multiple sequence alignment method with reduced time and space complexity. BMC Bioinformatics 5:113. http://www.biomedcentral.com/1471-2105/5/113

13. Elia, M. 1964. La "fusariosi" delle olive in Puglia. Phytopathol. Mediterr. 3:34-37.

14. Felsenstein, J. 2005. PHYLIP version 3.6. http://evolution.gs.washington. edu/phylip.html

15. Fisher, N. L., Burgess, L. W., Toussoun, T. A., and Nelson, P. E. 1982. Carnation leaves as substrate and for preserving cultures of Fusarium species. Phytopathology 72:151-153.

16. Geiser, D. M., Lewis Ivey, M. L., Hakiza, G., Juba, J. H., and Miller, S.A. 2005. Gibberella xylarioides (anamorph: Fusarium xylarioides), a causative agent of coffee wilt in Africa, is a previously unrecognized member of the G. fujikuroi species complex. Mycologia 97:191-201.

17. Gerlach, W., and Nirenberg, H. I. 1982. The Genus Fusarium-A pictorial atlas. Mitt. Biol. Bundesanst. Land-Forstwirsch. Berlin-Dahlem. 209:1406.

18. Giraud, T., Fournier, E., Vautrin, D., Solignac, M., Vercken, E., Bakan, B., and Brygoo, Y. 2002. Isolation of eight polymorphic microsatellite loci, using an enrichment protocol, in the phytopathogenic fungus Fusarium culmorum. Mol. Ecol. Notes 2:121-123.

19. Hong, S. G., Maccaroni, M., Figuli, P. J., Pryor, B. M., and Belisario, A. 2006. Polyphasic classification of Alternaria spp. isolated from hazelnut and walnut in Europe. Mycol. Res. 110:1290-1300.

20. Huelsenbeck, J. P., Bull, J. J., and Cunningham, C. W. 1996. Combining data in phylogenetic analysis. Trends Ecol. Evol. 11:152-158.

21. Hyun, J. W., and Clark, C. A. 1998. Analysis of Fusarium lateritium using RAPD and rDNA RFLP techniques. Mycol. Res. 102:1259-1264.

22. Kelly, K. L., and Judd, D. B. 1976. Color: Universal Language and Dictionary of Names. National Bureau of Standards, Spec. Publ. 440. Washington, DC.

23. Leslie, J. F., and Summerell, B. A. 2006. The Fusarium Laboratory Manual. Wiley-Blackwell Publishing Ltd., Oxford.

24. Mbofung, G. Y., Hong, S. G., and Pryor, B. M. 2007. Phylogeny of Fusarium oxysporum f. sp. lactucae inferred from mitochondrial small subunit, elongation factor $1-\alpha$, and nuclear ribosomal intergenic spacer sequence data. Phytopathology 97:87-98.

25. McKay, S. F., Freeman, S., Minx, D., Mayman, M., Sedgley, M., Collin, G. C., and Scott, E. S. 2009. Morphological, genetic, and pathogenetic characterization of Colletotrichum acutatum, the cause of anthracnose of almond in Australia. Phytopathology 99:985-995.

26. Mwang'ombe, A. W., Kipsumbai, P. K., Kiprop, E. K., Olubayo, F. M., and Ochieng, J. W. 2008. Analysis of Kenyan isolates of Fusarium solani f. sp. phaseoli from common bean using colony characteristics, pathogenicity and microsatellite DNA. Afr. J. Biotechnol. 7:1662-1671.

27. Nalim, F. A., Elmer, W. H., McGovern, R. J., and Geiser, D. M. 2009. Multilocus phylogenetic diversity of Fusarium avenaceum pathogenic on lisianthus. Phytopathology 99:462-468.

28. Nash, S. M., and Snyder, W. C. 1962. Quantitative estimations by plate counts of propagules of the bean root rot Fusarium in field soils. Phytopathology 52:567-572.

29. Nei, M., and Li, W.-H. 1979. Mathematical model for studying genetic variation in terms of restriction endonucleases. Proc. Natl. Acad. Sci. USA 76:5269-5273.

30. Nelson, P. E., Toussoun, T. A., and Marasas, W. F. O. 1983. Fusarium Species: An Illustrated Manual for Identification. Pennsylvania State University Press.

31. Nitschke, E., Nihlgard, M., and Varrelmann, M. 2009. Differentiation of eleven Fusarium spp. isolated from sugar beet, applying restriction fragment analysis of polymerase chain reaction-amplified translation elongation factor $1 \alpha$ gene fragment. Phytopathology 99:921-929.

32. Nye, T. M. W., Lio, P., and Gilks, W. R. 2006. A novel algorithm and webbased tool for comparing two alternative phylogenetic trees. Bioinformatics 22:117-119.

33. O'Donnell, K., and Cigelnik, E. 1997. Two divergent intragenomic rDNA ITS2 types within a monophyletic lineage of the fungus Fusarium are nonorthologous. Mol. Phylogenet. Evol. 7:103-116.

34. O’Donnell, K., Kistler, H. C., Cigelnik, E., and Ploetz, R. C. 1998. Multiple evolutionary origin of the fungus causing Panama disease of banana; concordant evidence from nuclear and mitochondrial gene genealogies. Pro. Natl. Acad. Sci. USA 95:2044-2049.

35. Ratnaparkhe, M. B., Tekeoglu, M., and Muehlbauer, F. J. 1998. Intersimple-sequence-repeat (ISSR) polymorphisms are useful for finding markers associated with disease resistance gene clusters. Theor. Appl. Genet. 97:515-519.

36. Santori, A., and Belisario, A. 2008. La necrosi grigia della nocciola: eziologia ed epidemiologia. Inf. Fitopatol. Suppl. Terra Vita 22:18-23.

37. Santori, A., Vitale, S., Luongo, L., and Belisario, A. 2010. First report of Fusarium lateritium as the agent of nut gray necrosis on hazelnut in Italy. Plant Dis. 94:484.

38. SAS Institute, Inc. 1990. SAS/STAT User's Guide, Release 6.07, Vol. 1. SAS Institute Inc., Cary, NC.

39. Summerell, B. A., Salleh, B., and Leslie, F. L. 2003. A utilitarian approach to Fusarium identification. Plant Dis. 87:117-128.

40. Swofford, D. L. 2002. PAUP*: Phylogenetic Analysis Using Parsimony *(and other methods). Version 4.0b10. Sinauer Associates, Sunderland MA.

41. Thompson, J. D., Higgins, D. G., and Gibson, T. J. 1994. CLUSTAL W: improving the sensitivity of progressive multiple sequence alignment through sequence weighting, position-specific gap penalties and weight matrix choice. Nucleic Acids Res. 22:4673-80.

42. Turner, A. S., Lees, A. K., Rezanoor, H. N., and Nicholson, P. 1998. Refinement of PCR-detection of Fusarium avenaceum and evidence from DNA marker studies for phenetic relatedness to Fusarium tricinctum. Plant Pathol. 47:278-288.

43. White, T. J., Bruns, T., Lee, S., and Taylor, J. 1990. Amplification and direct sequencing of fungal ribosomal RNA genes for phylogenetics. Pages 315-322 in: PCR Protocols: A Guide to Methods and Applications. M. A. Innis, D. H. Gelfand, J. J. Snisky, and T. J. White, eds. Academic Press, San Diego, CA

44. Wollenweber, H. 1931. Fusarium on walnut. Mitt. Deutsch. Dendrol. Gesellsch., XLIII (Jahrbuch).

45. Zaccardelli, M., Vitale, S., Luongo, L., Merighi, M., and Corazza, L. 2008. Morphological and molecular characterization of Fusarium solani isolates. J. Phytopathol. 156:534-541. 